\title{
Effect of turn preference upon development of discriminated T-maze training ability of infant mice*
}

\author{
Z. MICHAEL NAGY \\ Bowling Green State University, Bowling Green, Ohio 43403
}

Mice received 25 trials in a shock-escape T-maze at 7 , 9,11 , or 13 days of age. On the first trial, shock-offset occurred upon reaching either goalbox. For the remaining 24 trials, half of the mice at each age were trained to escape to the goal opposite their first-trial choice, while the other half continued to receive shock-offset for reaching either goalbox. Comparisons of direction of choice-point turns indicated little difference between trained and free-choice groups at 7 days of age. In contrast, mice trained to a specific goal at 9,11 , and 13 days of age made more turns in the direction opposite their first-trial choice than did the free-choice groups.

At a recent symposium on early learning, Campbell, Riccio, \& Rohrbaugh (1971) provided a comprehensive review of research dealing with the onset of learning capacities in very young organisms. Although evidence was reviewed that suggested instrumental learning capacities on a straight-alley shock-escape task as early as 5 days of age (Misanin, Nagy, \& Weiss, 1970; Nagy, Misanin, \& Newman, 1970), Campbell et al were skeptical of these data, since a running speed measure did not indicate improved escape performance until 13-15 days of age.

Nagy \& Sandmann (1973) have more recently confirmed the earlier findings of instrumental learning capacities appearing before 15 days of age by demonstrating learning and $24-\mathrm{h}$ retention capacities in mice by 11 days of age on a discriminated T-maze shock-escape task. Mice trained at 9 days of age, however, failed to differ from control groups on the retention test, suggesting a lack of 24-h memory capacity for this escape task. Although 9-day-old mice did show an increase in the number of "correct" turns during the original training session, it was not clear that learning had, in fact, taken place, inasmuch as the number of turns made in a particular direction at the choice-point did not differ from chance expectation at any point in the training session.

Since it was not determined whether mice at these ages exhibit a turn preference in the T-maze, it is possible that the comparison of the number of correct turns made by the trained mice against chance expectation was an inappropriate index of learning. The present study was designed to examine this possibility by comparing the performance of mice trained to escape to a particular goalbox with those allowed free-choice goal selection.

*This research was supported by Research Grant GB-30456 from the National Science Foundation.

\section{METHOD \\ Subjects}

The Ss were 128 Swiss-Webster albino mice (Mus musculus) born and reared in $30.4 \times 18 \times 12.8 \mathrm{~cm}$ polyethylene cages with wire-grid tops. Separate groups of 8 males and 8 females received one of two training procedures at $7,9,11$, or 13 days of age. The mothers remained with the mice at all times except during the training sessions and were on ad lib food and water. Temperature in the colony and test rooms was maintained at $24 \pm 1^{\circ} \mathrm{C}$.

\section{Apparatus}

The apparatus consisted of a Plexiglas T-maze, $6.2 \mathrm{~cm}$ high and $3.4 \mathrm{~cm}$ wide throughout. The stem section was $18.6 \mathrm{~cm}$ long, with a removable door $5 \mathrm{~cm}$ from the closed end, forming the startbox, and each goal arm was $9.2 \mathrm{~cm}$. The maze was placed upon a grid floor, constructed of 1-mm-diam stainless steel rods spaced $3 \mathrm{~mm}$ center-to-center, such that the grids were parallel with the stem of the maze and perpendicular to the length of the arms. A scrambled ac shock source (Harvard Instrument Co., Model 3121) delivered $.1-\mathrm{mA} 60-\mathrm{Hz}$ constant current to the grid floor.

\section{Procedure}

The training procedure consisted of placing the mouse into the startbox, facing the choice point. After $5 \mathrm{sec}$, the door was removed, shock initiated, and a running time meter started. Shock was continued until the mouse reached within $6 \mathrm{~mm}$ of the end of the "correct" goal arm. The shock and timer were then turned off, and the S was held in the E's closed hand for a 45-sec intertrial interval. The mouse was then replaced in the startbox for the next trial. Twenty-five trials were administered in the training session.

At each of the four ages, eight mice of each sex were assigned to either a trained or free-choice group according to a modified split-litter design. All groups received shock-offset upon reaching either goal on the first trial. On the following 24 trials, the trained groups received shock-offset only upon reaching the goal which was opposite their first-trial choice, while the free-choice groups continued to receive shock-offset for reaching either goal. Trained mice not reaching the "correct" goal within $300 \mathrm{sec}$ were gently forced to that goal, and shock was terminated. Free-choice mice failing to reach either goal within $300 \mathrm{sec}$ were forced to one of the goals and shock terminated. Goal selection was random for such trials for the free-choice groups.

The training measure utilized in the present study was the goal arm that each mouse entered (one-half body length) upon first reaching the choice-point on each trial. Turn at the choice-point was recorded for those mice requiring a forced trial if they had reached the choice-point and entered one of the goal arms within the $300-\mathrm{sec}$ trial period. Forced mice not reaching the choice-point received no score on that trial.

\section{RESULTS AND DISCUSSION}

The mean number of choice-point turns in the direction opposite the first-trial choice for Trials $2-25$ is presented in Fig. 1 as a function of training group, age, and blocks of four trials. The maximum number of choice-point turns is four per trial block. Examination of the free-choice groups' responses indicated that there was a slight but consistent turn preference at all ages, with all groups making $51 \%-61 \%$ of their turns during 


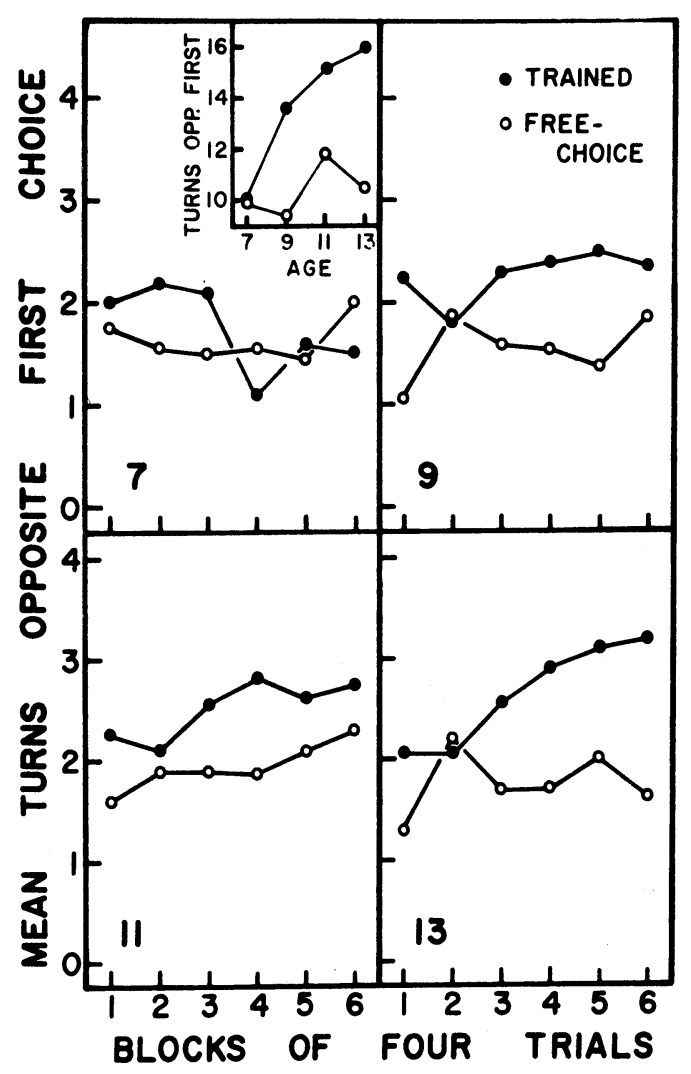

Fig. 1. Mean number of turns at the choice-point in the direction opposite the first-trial choice as a function of age, training group, and trial blocks.

the session in the same direction as their first turn. At 7 days of age, the trained group failed to overcome their preferred turn by the end of the training session, while all older trained groups appeared to make more turns in the direction opposite their first-trial choice as compared to their respective free-choice control groups.

An analysis of variance with one repeated measure conducted on these data indicated that overall the trained groups made more choice-point turns opposite their first choice than did the free-choice groups $(F=23.26 ; \mathrm{df}=1 / 112 ; \mathrm{p}<.0005)$, and that these turns increased as a function of age $(F=4.68 ; \mathrm{df}=3 / 112$; $\mathrm{p}<.01)$ and over trial blocks $(\mathrm{F}=2.38 ; \mathrm{df}=5 / 560$; $\mathrm{p}<.05$ ). To determine the effectiveness of training as a function of age, multiple comparisons were conducted on the total number of these turns made during the training session by the trained and free-choice groups at each age, as depicted in the Fig. 1 inset. The difference was negligible at 7 days of age $(F=0.28: d f=3 / 112)$, but highly reliable at all other ages (all $\mathrm{Fs}>5.45$; $\mathrm{df}=3 / 112 ; \mathrm{ps}<.005)$.

These findings confirm the earlier Nagy \& Sandmann (1973) study, which reported evidence of learning capacities on the discriminated T-maze task by 11 days of age, and extend those findings by demonstrating that 9-day-old mice are also capable of showing improvement on a discrimination task when innate turn preferences are accounted for. Although the turn preference was not very strong, it was consistent enough at all ages tested to suggest that the comparison of trained mice against chance expectation of direction of turn at a choice point is not an appropriate measure of learning at these early ages.

When the present results are considered in conjunction with the Nagy \& Sandmann (1973) findings, it appears that the onset of learning capacity for this discriminated escape task develops by 9 days of age in the mouse, while the onset of 24-h retention capacity occurs several days later, possibly requiring further maturation of the central nervous system. Although such a conclusion may be premature until additional parameters have been more fully explored, the present results do support the contention of the presence of learning capacities in mice younger than 15 days of age.

\section{REFERENCES}

Campbell, B. A., Riccio, D. C., \& Rohrbaugh, M. Ontogenesis of learning and memory: Research and theory. In M. E. Meyer (Ed.), Second Western Washington Symposium on Learning: Early Learning. Bellingham: Western Washington State College Press, 1971. Pp. 76-109.

Misanin, J. R., Nagy, Z. M., \& Weiss, E. M. Escape behavior in neonatal rats. Psychonomic Science, 1970, 18, 191-192.

Nagy, Z. M., Misanin, J. R., \& Newman, J. A. Anatomy of escape behavior in neonatal mice. Journal of Comparative \& Physiological Psychology, 1970, 72, 116-124.

Nagy, Z. M. \& Sandmann, M. Development of learning and memory of $T$-maze training in neonatal mice. Journal of Comparative \& Physiological Psychology, 1973, 83, 19-26.

(Received for publication A pril 2, 1973.) 